bioRxiv preprint doi: https://doi.org/10.1101/2020.11.18.388017; this version posted November $20,2020$. The copyright holder for this preprint (which was not certified by peer review) is the author/funder, who has granted bioRxiv a license to display the preprint in perpetuity. It is made available under aCC-BY-NC-ND 4.0 International license.

\title{
Title: Diet and heat - one neuronal subset two responses
}

Authors: Elodie Prince ${ }^{+}$, Jenny Kretzschmar, Laura C. Trautenberg and Marko Brankatschk*

Affiliations: Biotechnologisches Zentrum, Tatzberg 47/49 01307 Dresden, Germany

${ }^{+}$Present address : iBV - Institut de Biologie Valrose, CNRS UMR7277, Inserm U1091, UNS

- Bâtiment Centre de Biochimie, Faculté des sciences - Parc Valrose - 06108 Nice Cedex 2, France.

*Corresponding author: marko.brankatschk@tu-dresden.de

Keywords: Insulin signaling, AKT, MAPK, dietary lipids, metabolism, heat resistance

\begin{abstract}
The Insulin signal cascade is one of the best studied metabolic circuits, and shows a remarkable high molecular and functional conservation across the animal kingdom. Insulinproducing cells respond directly to nutritional cues in circulation and receive modulatory input from connected neuronal networks. Neuronal control is rapid and integrates a wide range of variables including dietary change or environmental temperature. However, despite various detailed studies that demonstrated the potential of neuronal regulation the physiological relevance of this circuit remains elusive.

In Drosophila, Insulin-like peptide 7 (dIlp7) -producing neurons are wired with Insulinproducing cells. We found a dual role for this neuronal subset: a.) activated dilp7-producing neurons are required to facilitate development at high temperatures, and if confronted with calorie-rich food that represses neuronal activity b.) their product, dIlp7, regulates Insulin signalling levels. Our work shows that Insulin-producing cells not simply integrate signals from circulating nutritional cues and neuronal inputs, but switch to neuronal control in response to dietary composition.
\end{abstract}

\section{INTRODUCTION}

Thriving in new ecological systems, Drosophila learned to utilize local food. Such resources vary in their composition in response to environmental temperature changes (13). Wild fruit flies feed on rotting fruits i.e. a composite diet of microbes and plants. As such food sources are erratic, adult fruit flies also feed on alternative carbohydrate sources, such as yeast-free pollen $(4,5)$. Pollen represents a type of calorie-rich plant food characterized by unsaturated fatty acids and phytosterols $(6,7)$. Previously, it has been shown that Drosophila struggle to survive on corresponding experimental diets at high temperatures (1) and that wild flies seek yeast-based food in the summer (3). Although global warming is the main problem our society is facing in this 21 st century, its consequence on the animal kingdom is not understood $(8,9)$. In this paper, we provide new insights in the dual response of one neuronal subset to diet and changes of environmental temperatures. With increasing temperatures, fruit flies accelerate their metabolism to acclimatize. By feeding on yeast, Drosophila can maintain high Insulin signaling (IS) levels required to shuttle efficiently nutritional cues (such as sugars in circulation) into cells $(1,10-12)$. Drosophila produces seven different $\underline{\text { Insulin-like peptides }}$ (dIlps) in response to dietary signals. The structure and function of dIlps, as well as the putative precursor protein, are similar to human Insulin and Insulin-like growth factor (IGF) peptides or pre-pro-Insulin, respectively; thus, implying an analogous organization of the final secreted peptide (12-14). Some dIlps play exclusive developmental roles, such as dIlp1 (15-17), dIlp 4 
(12) and dIlp8 (18-21), and their production is restricted in time. Others, such as dIlp6 are associated with nutritional disorders and counteract the group of canonical dIlp peptides (22). Adult flies express four neuronal dIlps: dIlp2,3,5 and 7. DIlp2,3 and 5,produced by neuronal Insulin-producing cells (IPCs), are secreted into circulation $(14,23)$ and resemble the functional role of the vertebrate Insulin, secreted by the pancreatic Beta cells (14). DIlp7 is produced by specialized dIlpz-neurons (D7Ns) and is the only dIlp peptide showing structural conservation across species $(13,24,25)$. Some D7Ns are wired with IPCs whereas others terminate in the periphery (23,26-29). Therefore, dIlp7 may regulate IS at multiple levels, by directly controlling IPC activity or stimulating the IS in the periphery $(23,27)$.

The intracellular IS cascade is conserved and consists of molecular components known from the vertebrate pathway $(13,30)$. Activated $\underline{\operatorname{Insulin}}$ receptor $(\mathrm{InR})$ recruits its adaptor protein, Chico - the functional counterpart of vertebrate Insulin receptor substrate (IRS) proteins - which conveys the signal into either the Ras- or PI3K-dependent pathway (31). The Ras-dependent pathway promotes mitogenic metabolism characterized by catabolic cellular turnover rates (32). PI3K signaling promotes anabolic processes that buildup cellular energy stores (33).

Here, we investigate IS in the scope ofdifferent diets and changing environmental temperatures. We show that yeast products can compensate for the loss of dIlp2, 3 and 5 at moderate temperatures. However, to endure heat stress, all three dIlps and yeast are required. In addition, we show that high intracellular Calcium $\left(\mathrm{Ca}^{2+}\right)$ levels in D7Ns are essential to develop at high temperatures. On yeast-free diets, D7Ns have low $\mathrm{Ca}^{2+}$ levels and in consequence, Drosophila, on such diets, do not develop.

We found that dIlp7 is essential to survive on yeast-free diet and identified the leucinrich repeat-containing $\underline{G}$ protein-coupled receptor $\underline{3}(\mathrm{Lgr} 3)$ as its potential target. We speculate that dIlp7/Lgr3 signalling is maintaining systemic IS levels by regulating dIlp2 and 5 activity. Taken together, we propose that D7Ns form a neurosecretory network essential to sustain Drosophila in absence of dietary yeast and changing environmental conditions.

\section{RESULTS}

\section{Yeast food is not sufficient to replace IPC activity at high temperatures}

Drosophila larvae kept on Yeast food (YF) show high systemic Insulin signalling (IS) levels, and can endure heat stress. It was shown that yeast lipids facilitate the secretion of Drosophila Insuline-like peptides (dIlps) but it remained unclear if high dIlp levels are essential to thrive at high temperatures (1). To test if Insuin-producing cell (IPC) activity is required for flies to survive in warm environments, we have silenced or hyper-activated IPCs by expressing either the inward rectifier potassium channel Kir2.1 (34) or the thermo-sensitive transient receptor potential cation channel, TRPA1 $(35,36)$. As expected, we found that on $\mathrm{YF}$, at $28^{\circ} \mathrm{C}$, IPC activity is essential for larval survival (Supplementary Figure S1). To investigate if IPC activity is required throughout larval development, we have induced IPC silencing at different larval stages. At high temperatures $\left(28^{\circ} \mathrm{C}\right)$, IPC activity is essential for larval survival, whereas continuous high calcium $\left(\mathrm{Ca}^{2+}\right)$ levels in these cells are of no consequence (Supplementary Figure S1). To investigate if IPC activity is required throughout larval development, we have induced IPC silencing at different larval stages. At $28^{\circ} \mathrm{C}$, high $\mathrm{Ca}^{2+}$ levels in IPCs are essential for larval survival at any tested time point (Supplementary Figure S1). To evaluate the contribution of individual dIlps, we have tracked the development of different $\Delta d I l p$ mutants at comfortable temperatures $\left(20^{\circ} \mathrm{C}\right)$ or upon heat stress $\left(28^{\circ} \mathrm{C}\right)$. At $20^{\circ} \mathrm{C}$, all tested mutants, including $\Delta d I l p^{2}, \Delta d I l p^{3}, \Delta d I l p^{5}, \Delta d I l p^{2-3}$ or $\Delta d I l p^{2-3,5}$, survive (at $20^{\circ} \mathrm{C}, \mathrm{n}_{\text {larva }}=132$, control $($ Cntr $)=132 \pm 0 \%$ and $\left.\mathrm{n}_{\text {larva }}=140, \Delta d I l p^{2-3,5}=72.1 \pm 4.3 \%, \mathrm{p}=* * * *\right)$; although the developmental 
rate of $\Delta d I l p^{2-3,5}$ is much slower and produces small larvae and pupae with respect to controls (Figure 1 and Supplementary Figure S1 and (37,38).

At $28^{\circ} \mathrm{C}$, tested $\Delta d I l p^{2}, \Delta d I l p^{3}$ or $\Delta d I l p^{5}$ larvae, kept on $\mathrm{YF}$, show no developmental defects (Supplementary Figure S1). However, we found that heat stress slows the developmental rate and reduces survival of $\Delta d I l p^{2-3}$, and that a majority of $\Delta d I l p^{2-3,5}$ animals perish (Figure 1).

Yeast-free food fed animals have limited IPC activity, low systemic IS levels and show decreased survival at high temperatures (1). To rule out the effects of yeast products, we have

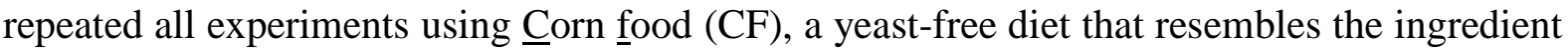
proportions found in YF ((39); Table 1 and Table 2, respectively). At $28^{\circ} \mathrm{C}$, controls are unable to survive on CF. Furthermore, induced expression of dIlp2 in IPCs is only in part promoting larval development (Supplementary Figure S1). Taken together, to mount an effective heat response, Drosophila relies on dietary yeast products and its complement of IPC dIlp peptides.

\section{DIlp7-neurons are required to provide heat resistance in Drosophila}

DIlp7- producing neurons (D7Ns) are wired with IPCs in larval and adult stages and have a modulative function $(23,26,27)$. To test if D7N activity influences the resistance to high temperatures, we have silenced these cells and tracked larval development on $\mathrm{YF}$ at $28^{\circ} \mathrm{C}$. We found that low D7N activity results in reduced larval survival (Figure 1). However, the developmental speed of surviving animals is comparable to controls (Supplementary Figure S1). Drosophila kept on yeast-free food show low IS levels and are sensitive to heat stress (1). Therefore, we speculated that D7N, on such yeast-free diets, mightbe inactive and that induced D7N activity could increase heat resistance. To test our idea, we expressed the fluorescent $\mathrm{Ca}^{2+}$ reporter, GCaMP, in D7Ns in larval brain tissues (10). We found that D7N never show high $\mathrm{Ca}^{2+}$ levels on CF contrary to flies kept on YF (Figure 1). To increase $\mathrm{Ca}^{2+}$ yields in D7Ns, we expressed the temperature-sensitive $\mathrm{Ca}^{2+}$ channel, TRPA1, and assayed the survival of larvae kept on yeast-free CF ((39) and Table recipes). Interestingly, survival rates of $d I l p^{7}>>T R P A 1$ (TRPA1) larvae increased significantly (Figure 1). To investigate if dIlp7 is essential to provide heat resistance, we tracked $\Delta d I l p^{7}$ larvae at $20^{\circ} \mathrm{C}$ and $28^{\circ} \mathrm{C}$. We found that $\Delta d I l p^{7} \mathrm{kept}$ on YF show no phenotypes; however, $\Delta d I l p^{7}$ are unsuccessful on CF (Figure 2 and Supplementary Figure S2). We conclude that D7Ns are required to acclimatize at high temperatures. In addition, although not involved in temperature response, dIlp7 peptide produced by D7Ns is essential to promote survival on yeast-free diets.

\section{On yeast-free food, dIlp2 and dIlp7 are negative regulators of dIlp5}

To investigate the role of dIlps in animals feeding on yeast-free diets, we performed a metabolic screen of $\Delta d I l p$ mutants on $\mathrm{CF}$ at $20^{\circ} \mathrm{C}$. We found that, in addition to $\Delta d I l p^{7}$, three other mutants struggle to thrive on $\mathrm{CF}$, including $\Delta d I l p^{2}, \Delta d I l p^{3}$ and $\Delta d I l p^{5}$ (Figure 2). To evaluate potential genetic interactions between dIlp7 and each of these candidates, we have created $\Delta d I l p^{2,7}, \Delta d I l p^{3,7}$ and $\Delta d I l p^{5,7}$ double mutants. Astonishingly, the absence of dIlp2 and dIlp7 restored survival rates close to numbers shown by controls. In contrast, $\Delta d I l p^{3,7}$ and $\Delta d I l p^{5,7}$ animals did not perform better and $\Delta d I l p^{2,3}$ were unable to develop on CF (Figure 2; Supplementary Figures S1 and S2). To test, if the loss of dIlp2 and dIlp7 hyper-activates dIlp3 or dIlp5, we assayed the development of $\Delta d I l p^{2-3,5}$ and $\Delta d I l p^{2-3,7}$ triple mutants. In contrast to $\Delta d I l p^{2-3,5}, \Delta d I l p^{2-3,7}$ were able to survive on CF alike $\Delta d I l p^{2,7}$ or control larvae (Figure 2).

The presence of dIlp7 is required for survival on CF but not for individuals kept on YF. Hence, we tested the idea that yeast products compensate for the regulative role of dIlp7. To do so, we reared all created $\Delta d I l p$ mutants onto YF. We found that at $20^{\circ} \mathrm{C}, \Delta d I l p^{5,7}$ are less successful, but did not reduce their developmental speed (Supplementary Figure S2). The 
lethality of $\Delta d I l p^{2-3,5}$ is comparable to $\Delta d I l p^{5,7}$; however, these triple mutants develop slower (Figure 1; Supplementary Figures S1 and S2). Although delayed in development, the survival of $\Delta d I l p^{2-3,7}$ is not affected (Figure 2). Pupae of both triple mutants are small in size (Supplementary Figure S1).

In conclusion, the data from our work indicate that on $\mathrm{CF}$, dIlp5 can compensate for the loss of all other neuronal dIlps expressed in larval stages. Our findings crystallize dIlp2 and dIlp7 as negative regulators of dIlp5.

\section{DIlp7 is instructive for larval and adult feeding behavior on CF}

Feeding behavior and intestinal food transit are two connected variables that can modulate the absorption efficiency of food compounds. It was shown that Drosophila, with genetically silenced D7Ns, change their feeding behavior with respect to controls (27). To test the feeding behavior of $\Delta d I l p$ mutants, we have measured larval mouth-hook contractions (40), and the appearance or disappearance of ingested color in the adult intestinal tracts (27). Transferred on CF, mouth-hook contractions of all tested dIlp mutants appeared slightly faster with respect to controls. Nevertheless, we found that ingestion of stained food in $\Delta d I l p^{7}$ mutant larvae takes longer compared to controls. (Supplementary Figure S2). To test if $\Delta d I l p^{7}$ adults show the same feeding behavior on CF, we recorded how fast colored food is consumed. $\Delta d I l p^{7}$ flies feed faster, but need more time to excrete material compared to controls (Figure 3). Interestingly, we have discovered a similar behavior for $\Delta d I l p^{2}$ mutants feeding on $\mathrm{CF}$ (Supplementary Figure S2). Taken together, these data show that dIlp7 and dIlp2 are important for larva and adult feeding behavior on yeast-free diet.

\section{DIlp7 and not dIlp2 regulates systemic Insulin signaling on CF}

Food transition time might be critical for efficient absorption of nutrients, therefore we predicted that $\Delta d I l p^{2}$ and $\Delta d I l p^{7}$ mutants will show similar activity of metablic circuits such as the IS cascade. The phosphorylation state of AKT and MAPK allows to quantify the activity of anabolic and mitogenic IS activity, respectively. Therefore, we probed the phosphorylation state of $\mathrm{AKT}^{85}$ and MAPK in adults, fed on CF, by western-blotting. We found that the $\mathrm{AKT}^{85-}$ Thr342 phosphorylation state remains unchanged in all tested genotypes (Supplementary Figure $\mathrm{S} 3$ ). In contrast, we detected reduced phosphorylation at the $\mathrm{AKT}^{85-\mathrm{Ser} 505}$ site of all tested $\Delta d I l p^{7}$ mutant genotypes and $\Delta d I l p^{2-3}$ mutants, while the $\mathrm{AKT}^{85}$ activity of $\Delta d I l p^{2}, \Delta d I l p^{3}$ and $\Delta d I l p^{5}$ mutants remains unchanged (Figure 3). In addition, we detected reduced MAPK phosphorylation for all $\Delta d I l p$ loss-of-function genotypes (Supplementary Figure S3). For comparison we repeated experiments performed on CF with YF to compare the activity of $\mathrm{AKT}^{85}$ and MAPK. We did not detect any meaningful phenotypes in most of $\Delta d I l p$ mutant regarding larval development and adult $\Delta d I l p$ mutants thrive on YF like controls (Supplementary Figure S3). Thus, we expected that neither $\Delta d I l p$ mutant shows differences in the activity of either enzyme compared to controls. We found that all tested genotypes kept on YF show similar AKT or MAPK phosphorylation levels (Supplementary Figure S3). Taken together, we conclude that YF compensates for the loss of individual dIlps. In contrast, on yeast-free diet (CF), adult flies rely on dIlp7 to adjust their feeding behavior and to maintain basic AKT and MAPK activity required to survive (data not shown).

\section{Lgr3 represents a potential target for dIlp7 on Insulin-producing cells}

We speculated that on yeast-free food, dIlp7 regulates IPC activity by activating one of its three predicted candidate receptors: the Drosophila Insulin-like receptor (dInR) (12), or one of the two predicted $\underline{\mathrm{G}}$-protein coupled receptors (GPCR), Leucine-rich repeat-containing $\underline{G}$ protein-coupled receptor $\underline{3}(\mathrm{Lgr} 3)$ and $\underline{4}(\mathrm{Lgr} 4)(41,42)$. We decided to targeteach receptor in IPCs, by RNA interference (RNAi) using published validated genetic tools (43). The reduction 
of the dInR ( $\mathrm{InR}^{\mathrm{KD}}$ ) or $\mathrm{Lgr} 4\left(\mathrm{Lgr} 4^{\mathrm{KD}}\right)$ did not produce any phenotypes. $\mathrm{InR}^{\mathrm{KD}}$ and $\mathrm{Lgr} 4^{\mathrm{KD}}$ larvae developed as fast as controls; however, $\mathrm{InR}^{\mathrm{KD}}$ individuals show a slight decrease in survival on both YF and CF compared to controls (Supplementary Figure S4). In contrast, we found that the loss of $\mathrm{Lgr} 3\left(\mathrm{Lgr}{ }^{\mathrm{KD}}\right)$ slowed the development on $\mathrm{YF}$ and decreased pupariation success on CF (Figure 4).

One accessible marker for stored cellular energy is the Triacylglyceride (TAG) level stored in lipid droplets. High IS levels correlate with high TAG yields. To test the idea that loss of Lgr3 reduces IS and hence, produces fewer TAGs, we have analysed lipid profiles of adult flies kept on YF. We found, that $\mathrm{Lgr} 3^{\mathrm{KD}}$ store less lipids with respect to controls (Supplementary Figure S4) indicating lower anabolic turnover rates. To investigate if Lgr3 modulates systemic IS, we probed the phosphorylation of $\mathrm{AKT}^{85}$ and MAPK in $\mathrm{Lgr}{ }^{\mathrm{KD}}$ flies. We found that $\mathrm{AKT}^{85}$ phosphorylation of $\mathrm{Lgr} 3^{\mathrm{KD}}$ adults kept on $\mathrm{YF}$ at $20^{\circ} \mathrm{C}$ remained unchanged (Figure 4). On $\mathrm{CF}$, the $\mathrm{AKT}^{85-\mathrm{Ser} 505}$ phosphorylation was reduced to levels assimilable to tested $\Delta d I l p^{7}$ mutant backgrounds (Figures 3 and 4). However, Lgr ${ }^{\mathrm{KD}}$ MAPK activity remained comparable to controls (Figure 4) indicating that dIlp7 should regulate MAPK by other means than Lgr3 expressed by the IPCs. Although of indirect evidence, our data lead us to the conclusion that on yeast-free diets, systemic IS is regulated by Lgr3 expressed in the IPCs.

\section{DISCUSSION}

Drosophila expresses four neuronal Insulin-like peptides (dIlps) and we analyzed here the physiological role of dIlp7 produced by the dIlp7-neurons (D7Ns). We found that active D7Ns facilitate Insulin signalling (IS) and therefore, represent one component of a hightemperature-sensitive neuronal network similar to already described regulative circuits (4446). Nonetheless, $\Delta d I l p^{7}$ mutants thrive at high temperatures similar to respective controls confirming that dIlp7 peptide is not crucial to withstand thermal treatment. We found that dIlp7 is essential to modulate IS in flies feeding on yeast-free diet, a food that allows only for low D7N activity and changes flies heat sensitivity.

Adult flies switch their feeding behavior in response to temperature and prefer yeastfree plant food during periods of cold temperatures $(1,3)$. Moreover, Drosophila kept on plant food are unable to endure heat stress. We show that on corn food (CF), D7Ns have low calcium $\left(\mathrm{Ca}^{2+}\right)$ levels and induced activity of these cells enables more animals to survive heat. Interestingly, we found high dIlp7 levels in D7Ns regardless of the dietary input (Supplementary Figure S5). Hence, we wondered if dIlp7 plays any role for Drosophila feeding on yeast-free food. We show that the developmental success of $\Delta d i l p^{7}$ is strongly reduced on $\mathrm{CF}$ with respect to controls. It was shown that dIlp7 expression is strongly dependent on nutritional variables including protein:sugar ratio and caloric load (47). CF is rich in calories, its protein:sugar ratio is optimized and contains about $10 \%$ lipids ((39) and Table 1). Nevertheless, on CF, systemic Insulin levels are low and wild-type larvae struggle to complete their development $(39,48)$. Astonishingly, we found that the absence of both dIlp2 and dIlp7 improved larval survival on CF up to numbers shown by controls. DIlp2 and dIlp5 have been described as highly redundant and target identical dIlp binding proteins (13). Nevertheless, the survival rate of $\Delta d I l p^{5,7}$ mutants kept on $\mathrm{CF}$ is low; thus, implicating that dIlp5 plays a different biological role than dIlp2 (49,50). In addition, $\Delta d I l p^{2-3,7}$ mutants are as successful as $\Delta d I l p^{2,7}$; thus, ruling out dIlp3 as a determining factor. Moreover, our results position dIlp5 as sufficient to rescue development since $\Delta d I l p^{2-3,5}$ and $\Delta d I l p^{2-3}$ hardly grow on CF. Taken together, on yeast-free food, larval development is controlled by dIlp7, which may regulate the activity of dIlp2 and 5. 
To better understand how possibly dIlp7 regulates the activity of the IPC-produced dIlp2 and dIlp5, we have investigated three predicted targets of dIlp7 including the Drosophila Insulin-like receptor (dInR) and the two $\underline{G}$ protein-coupled rectors GPCRs, Lgr3 and 4 $(12,41,42)$. We found that the knock-down of Lgr3 in IPCs results in lower larval survival on $\mathrm{CF}$. It is shown that Lgr3 is targeted by dIlp8 and plays an important role in larval development $(18,21)$. However, $\Delta d I l p^{8}$ mutants performed as controls on CF (Supplementary Material/Excel sheet/dIlp mutants_Survival_CF20) and AKT ${ }^{85-S e r 505}$ phosphorylation of adult Lgr3 ${ }^{\mathrm{KD}}$ is reduced to numbers shown by all tested $\Delta d I l p^{7}$ background mutants. On the other hand, measured MAPK activity of $\operatorname{Lgr} 3^{\mathrm{KD}}$ is comparable to controls. This result is contrasting findings made with $\Delta d I l p^{7}$ mutants, and we propose that secreted dIlp7 enters circulation $(23,26)$ and regulates the mitogenic branch of the IS cascade. Nevertheless, future studies are required to demonstrate direct dIlp7/Lgr3 interaction at the molecular level.

Neuronal innervation of IPCs is established in many animals and modulates metabolic signals $(23,45,51,52)$. Our findings indicate that food products can overwrite neuronal stimulation of IPCs. In Drosophila, we found a dual role for D7Ns: i.) these neurons facilitate the heat response of flies feeding on yeast and ii.) they form a metabolic circuit that enables adult flies to thrive on yeast-free diets if required. In mice and humans, pancreatic islets are directly innervated $(51,52)$; however, the role of this neuronal stimulation in response to dietary cues is not understood. We have identified D7Ns and their product, dIlp7, important to regulate IS independently from the provided high caloric load and abundance in dietary sugars or proteins. Our findings provide new insights into the neuronal stimulation of Insulin-producing cells within a given ecological context and open the perspective to screen for nutritional cues capable to convey dietay signals to the brain.

\section{MATERIAS AND METHODS}

\section{Stocks}

If not stated, stocks were raised on normal food at $20-22^{\circ} \mathrm{C}$ (Table 3 ).

The following lines were used:

OregonR (\#5), w;foxo[mCherry] (\#80565) were provided by Bloomington Drosophila Stock Center (BDRC). Isogenized Canton $S$ were shared by J.C. Billeter. $w^{1118}$ and $y w$ were provided by S. Eaton's laboratory.

Drosophila Insulin-like peptide mutants: $\Delta d i l p^{1}-\Delta d i l p^{8}, \Delta d i l p^{2-3}$ and $\Delta d i l p^{2-3,7}((13)$; from S. Grönke); $\Delta$ dilp ${ }^{2-3,5}$ from R. Kühnlein.

Gal4 lines: w;dilp2-Gal4 ((14); \#37516 from BDRC); w;dilp7-Gal4 ((27); gift from I. MiguelAliaga); w;rab3-Gal4 and w;moody-Gal4 (from S.Eaton); $y w$;actin-Gal4(\#4414, from BDRC) UAS-lines: w;UAS-TrpA1 (\#26264, from BDRC); w;UAS-Kir2.1-egfp,tub80ts (from S.Eaton); $y w ; U A S-D i l p 2$ ((11); \#80936 from BDRC); w;UAS-GcAMP (\#32116 from BDRC); $y w ; U A S$ Dilp3 and $y w ; U A S-D i l p 5$ (from S.Eaton); w;UAS-Dilp7 (gift from I. Miguel-Aliaga); $y w ; U A S$ $I R^{D N}$ (\#8253, from S.Eaton); w;UAS-Lgr4RNAis (v102681 and v108915; Vienna Drosophila Resource Center (VDRC)); w;UAS-Lgr3shRNA (v330603; from VDRC).

\section{Diets}

Normal food was adapted from https://bdsc.indiana.edu/information/recipes/bloomfood.htm.l. (Table 3)

Yeast food was prepared as published by Brankatschk et al., 2018 (1) (Table 2).

Corn food recipe is described in Table 1 and in Trautenberg et al. 2020 (39).

\section{Development tracking experiments}


Embryos were collected overnight on apple-juice agar plates (25\% apple-juice, $1.5 \%$ agar, $0.4 \%$ p-Hydroxybenzoic acid methyl ester (nipagin)), bleached in $80 \%$ bleach/water for 30 seconds, rinsed and kept for 24 hours on starvation plates (25\% apple juice, $10 \%$ Glucose, $1.5 \%$ agar, $0.4 \%$ nipagin) at $20-22^{\circ} \mathrm{C}$. First-instar larvae were pipetted in $10 \mu \mathrm{L} 0.00005 \%$ TritonX100/PBS solution and transferred in 96 well-plates containing food. One larva per well (containing $200 \mu \mathrm{L}$ of food) was deposited. Later, the plates were sealed with a poked ventilated plastic film and put in incubators set at the temperature of interest. Both developmental speed/rate (how many days each larva took to reach the pupal stage) and success (how many larvae succeed to reach the pupal stage on the total number of larvae plated on one plate).

Induction experiments: The egg progeny of crosses between UAS-Kir2.1 or Canton $S$ and dilp2-Gal4, dilp7-Gal4 or Canton $S$ were collected. Larvae and plates were prepared as described above. Plates were kept at $20^{\circ} \mathrm{C}$ for 24,72 or 96 hours and then transferred to the $28^{\circ} \mathrm{C}$-incubator.

\section{Statistics}

Developmental success: For $20^{\circ} \mathrm{C}$ or $28^{\circ} \mathrm{C} /$ induction experiments, only experiments with minimum ten or six larvae tracked, respectively, were taken into account in the pool of data. Experiments out of the range (i.e. Mean + or - Standard deviation) were excluded of the normalized data. Mann-Whitney or Kruskal-Wallis tests were performed as statistical tests (PRISM Graphpad software).

Developmental speed: only speed data from experiments taken into account in the normalized data of the survival rates were picked. Mann-Whitney or Kruskal-Wallis tests were performed as statistical tests (PRISM Graphpad software).

\section{Immunohistochemistry}

The larvae were dissected, turned as socks in fix solution and kept in fix solution for 20 minutes. The carcasses were stained by HrpCy5 (HRP-S5-1; NANOCS) or with DAPI (mounted in Vectashiel medium containing DAPI, vectorlab). The central nervous systems were dissected from the carcasses and mounted in 50\% Glycerol/PBS. Confocal microscopy was performed on a Zeiss confocal laser scanning microscope LSM 700 of the Light Microscopy Facility, a Core Facility of the CMCB Technology Platform at TU Dresden. Antibody used: anti-dIlp7 (gift from Irene Miguel-Aligua, (27))

\section{GCaMP experiments}

Sample collection

The egg progeny of crosses between UAS-GCaMP or Canton S and dilp2-Gal4 or dilp7-Gal4 were collected. Larvae were prepared as described above in "developmental tracking part". Three larvae were pipetted in $10 \mu \mathrm{L} 0.00005 \%$ Triton-X100/PBS solution and transferred in 24 well-plates containing food. Three larvae per well (containing $1 \mathrm{~mL}$ of food) were deposited. Fed larvae were collected after being reared for 6 or 22 days on yeast food or corn food, respectively.

Immunostaining

Performed as described in "Immunochemistry" part. Quantifcation The total number of dilp2- or dilp7-GCaMP-postive (i.e. green-fluorescent cells) were counted in each brain imaged. The percentage of cells ON was then calculated on the total number of dilp2-positive cells (i.e. 8 per hemisphere (14) or dilp7-positive cells (i.e. 12 (26)). Statistics, Wilcoxon's test.

\section{Larva and adult weight}


To determine the weight of larvae or adults reared on yeast food, a determined number of thirdinstar larvae or adults were put in Eppendorf $2 \mathrm{~mL}$ tubes. Mass of one larva or one adult $(\mathrm{mg} / \mathrm{larva}$ or mg/adult, respectively $)=$ (Mass of the tube containing $\mathrm{x}$ number of larvae or adults $(\mathrm{mT}+\mathrm{xL}$ or $\mathrm{mT}+\mathrm{xA}$, respectively) - mass of the tube $(\mathrm{mT})) / \mathrm{x}$ number of larvae or adults contained in the tube (xL or $x A$, respectively).

\section{Pupa area}

Pupa arising from larvae reared in 96 -well plates containing yeast food at $20^{\circ} \mathrm{C}$ were placed on microscope slides were a $5 \mathrm{~mm}$-scale bars were drawn. Pictures were taken with a camera and processed by using Fiji (53). By using the "freehand" tool, the area of each pupa was measured. Kruskal-Wallis tests were performed as statistical tests.

\section{Feeding behavior}

\section{Larva mouth contraction}

Third-instar larvae fed on normal food were rinsed and transferred to three Petri dishes containing $0.5 \%$ Bromophenol-Blue colored yeast food or corn food (27). On each plate, 10 larvae were placed. The number of mouth contraction were counted within 30 seconds for each larva. Kruskal-Wallis tests were performed as statistical tests.

Larva food intake

Third-instar larvae fed on normal food were rinsed and transferred to three Petri dishes containing $0.5 \%$ Bromophenol-Blue colored yeast food or corn food (27). On each plate, 10 larvae were placed. Every 5 minutes, the number of larvae with blue guts were counted. Finally, the time to reach $100 \%$ of the larvae with blue guts per plate was plotted. Kruskal-Wallis tests were performed as statistical tests.

Adult food intake

Seven-to-ten days old adults starved for 24 hours were transferred in vials containing $5 \mathrm{~mL}$ $0.5 \%$ Bromophenol-Blue colored yeast food or corn food (27). The male:female ratio per vial was 1:3. Every 30 minutes, the number of females with blue guts were counted. Finally, the percentage of females with blue guts after 4 hours on the diet was plotted. Statistics, experiments out of the range (i.e. Mean + or - Standard deviation) were excluded of the normalized data. Kruskal-Wallis tests were performed as statistical tests.

\section{Adult transit}

Seven-to-ten days old adults kept for $24-48 \mathrm{~h}$ into vials containing $5 \mathrm{~mL}$ 0.5\%BromophenolBlue colored yeast food or corn food (27) were transferred into vials containing starvation diet ( $25 \%$ apple juice, $10 \%$ Glucose, $1.5 \%$ agar, $0.4 \%$ nipagin). The male:female ratio per vial was 1:3. Every 30 minutes, the number of females without blue guts were counted. Finally, the percentage of females without blue guts after 4 hours on starvation was plotted. Statistics, experiments out of the range (i.e. Mean + or - Standard deviation) were excluded of the normalized data. Kruskal-Wallis tests were performed as statistical tests.

\section{Biochemistry}

AKT detection in yeast and corn-food fed adult heads

Sample preparation, western-blotting and quantification were performed as published by (48). In brief, flies were raised on normal food and $5 \mathrm{~d}$ old adults transferred onto respective experimental foods for $7 \mathrm{~d}$ at $20^{\circ} \mathrm{C}$. Thereafter, flies were snap-frozen in liquid nitrogen and frozen heads from females collected for processing. Heads were homogenized on ice in $0.01 \%$ Tx100-PBS and subsequently cooked at $95^{\circ} \mathrm{C}$ for $5 \mathrm{~min}$. Polyclonal antibodies used to probe were Akt-pSer505 (Cell Signaling, 4054S), Akt-pThr308 (Invitrogen, 44-602G), Akt (Invitrogen, MAS14916), MAPK (Cell Signaling, p44/42 MAPK (Erk1/2) Antibody \#9102), 
bioRxiv preprint doi: https://doi.org/10.1101/2020.11.18.388017; this version posted November 20, 2020. The copyright holder for this preprint (which was not certified by peer review) is the author/funder, who has granted bioRxiv a license to display the preprint in perpetuity. It is made available under aCC-BY-NC-ND 4.0 International license.

P-MAPK (Cell Signaling, Phospho-p44/42 MAPK (Erk1/2) (Thr202/Tyr204) Antibody \#9101).

\section{Quantification}

Pixel intensity of defined area (line) covering the signature (not saturated) center on photograph was measured using FIJI software (53). Intensity ratio between AKT85-Ser505 and panAKT85 or P-MAPK and MAPK was calculated and normalized to value obtained from controls.

\section{Trehalose, protein and triacylglyceride quantification in larva or adult hemolymph}

Sample collection and preparation

Larvae: third-instar larvae raised in 96-well plates containing YF were collected, rinsed, drained, transferred in $2 \mathrm{ml}$ Eppendorf tubes and short-frozen in liquid nitrogen. Each tube was filled with 20 larvae. To collect hemolymph, $60 \mu \mathrm{L}$ of ice-cold1xPBS was added into the tube containing larvae. After spinning for 5 minutes at $500 \mathrm{~g}, 50 \mu \mathrm{L}$ of the supernatant were pipetted and transferred into another Eppendorf tube.

Adults: eight-to-ten days old adults reared on yeast food were collected, transferred into $2 \mathrm{~mL}$ Eppendorf tubes and short frozen in liquid nitrogen. For trehalose assay, 460 adults were required (male: female ratio $\approx 230: 230$ ); for protein quantification, 16 adults (male: female ratio $\approx 4: 12$ ) and for triacylglycerides, 9 adults were needed (male: female ratio $\approx 3: 6$ ). To collect hemolymph, $110 \mu \mathrm{L}$ of ice-cold $1 \mathrm{xPBS}$ was added to a tube containing sample flies. Samples were incubated on ice for 5 minutes and centrifuged for 10 seconds (benchtop centrifuge) two times, then $100 \mu 1$ of the supernatant was transferred to a fresh tube......

Trehalose assay and quantification

Hemolymph samples were heated at $85^{\circ} \mathrm{C}$ for 15 minutes. Then samples were cooled down to room temperature, and trehalose was measured and quantified like recommended by the manufacturer (Trehalose Kit, Megazyme).

Protein assay and quantification

Proteins in hemolymph samples were concentrated by choroform-methanol precipitation and re-dissolved in $0.1 \%$ TritonX100 in 1xPBS. Protein amount was measured and quantified like recommended by manufacturer (Pierce ${ }^{\mathrm{TM}}$ BCA Protein Assay Kit,Thermo Fisher Scientific).

Thin layer chromatography (TLCs)

Lipid extraction were performed as described by Bligh and Dyer $(54,55)$ and analyzed on TLC plates using published solvent protocols (polar lipids: $\mathrm{CHCl} 3: \mathrm{CH} 3 \mathrm{OH}: \mathrm{H} 2 \mathrm{O}$ (75 : $25: 2.5)$; neutral lipids: $\mathrm{C} 7 \mathrm{H} 16:(\mathrm{C} 2 \mathrm{H} 5) 2 \mathrm{O}: \mathrm{CH} 3 \mathrm{COOH}(70: 30: 1))$ Plates were stained with CuSO4 or Primulin and scanned using a Typhoon reader. Three homogenized fly heads per sample, $1 \mu \mathrm{L}$ lipid extract was pipetted on HPTLC Silica gel glass plates (Merck). Twenty larvae per sample, volume to resupend the lipid pellets was normalized to the larval weight and $3 \mu \mathrm{L}$ lipid extract was pipetted on HPTLC Silica gel glass plates (Merck). Triacylglycerol (TAG) $(10 \mathrm{mg} / \mathrm{ml})$ and Diacylglycerol (DAG) $(1 \mathrm{mg} / \mathrm{ml})$ were used as standards.

Triacylglycerides quantification

Pixel intensity of defined area (round) covering triglycerides signatures on photograph was measured using FIJI software (53). Intensity was calculated and normalized to the blank value.

\section{AKNOWLEDGMENTS}

We thank Suzanne Eaton, Irene Miguel-Aliaga and Ronald P. Kühnlein for sharing material. We thank Irene Miguel-Aliaga and her group for their feedback and advices on this project. We thank Mandy Obst for helping with the larva tracking and with lab organization. This work was supported by the Light Microscopy Facility, a Core Facility of the CMCB Technology Platform at TU Dresden. We thank Uenal Coskun's, Andrej Schevchenko's and Joerg 
Mansfeld's lab members for their help, advice and comments on this project. We thank Julien Marcetteau for his advices and help with figures.

\section{FUNDINGS}

This was work was supported by the Deutsche Forschungsgemeinschaft (DFG) [BR5492/1, FOR2682-TP4].

\section{COMPETING INTERESTS}

The authors declare no competing or financial interests

\section{AUTHOR CONTRIBUTION}

Conceptualization: M.B., E.P.; Formal analysis: E.P.; Funding acquisition: M.B.; Investigation: E.P., J.K., L.C.T.; Methodology: E.P.; M.B.; Project administration: M.B., E.P.; Resources: E.P., M.B.; Supervision: E.P., M.B.; Validation: E.P.; Visualization: E.P.; WritingOriginal Draft Preparation: M.B., E.P., J.K., L.C.T.

\section{TABLES}

\begin{tabular}{|c|c|c|c|c|c|}
\hline Corn Food (CF) (1L) & Quantity & kcal & $\begin{array}{l}\text { protein } \\
\text { (kcal) }\end{array}$ & $\begin{array}{c}\text { carbohydrates } \\
\text { (kcal) }\end{array}$ & $\begin{array}{c}\text { lipid } \\
\text { (kcal) }\end{array}$ \\
\hline Glucose (g) & 30 & 116.1 & 0 & 114.24 & 0 \\
\hline Sorbitol (g) & 18 & 43.2 & 0 & 43.2 & 0 \\
\hline Arabinose $(\mathrm{g})$ & 15 & 0 & 0 & 0 & 0 \\
\hline Yellow cornmeal $(\mathrm{g})$ & 65 & 224.9 & 20.8 & 182 & 17.55 \\
\hline Fructose (g) & 20 & 80 & 0 & 79.2 & 0 \\
\hline Malt extract $(\mathrm{g})$ & 15 & 55.05 & 3.6 & 57.72 & 0 \\
\hline Soy pepton (g) & 70 & 256.2 & 119 & 8.68 & 129.15 \\
\hline Sucrose (g) & 15 & 60 & 0 & 60 & 0 \\
\hline Agar $(g)$ & 8 & 2.08 & 0.16 & 2.24 & 0 \\
\hline Water (mL) & \multicolumn{5}{|c|}{ fill until $1 \mathrm{~L}$} \\
\hline $0.1 \mathrm{~g} / \mathrm{mL}$ Nipagin/EtOH (mL) & 40 & \multicolumn{4}{|c|}{ Add at $60^{\circ} \mathrm{C}$} \\
\hline & kcal & 837.53 & 143.56 & 547.28 & 146.7 \\
\hline & \multicolumn{2}{|c|}{$\%$} & $17 \%$ & $65 \%$ & $18 \%$ \\
\hline
\end{tabular}

\begin{tabular}{|c|c|}
\hline P:C:Li ratio & $1: 4: 1$ \\
\hline $\mathrm{P}: C$ ratio & $1: 4$ \\
\hline
\end{tabular}

Table 1. Corn food recipe

Recipe for 1 liter of corn food. The calories (in kcal) brought by each ingredient have been also calculated. At the bottom, in black bold, the totals (in kcal) are shown. In blue are indicated the proportion $(\%)$ of kcal of protein, carbohydrates or lipids on the total of amount calories. In purple are shown the protein: carbohydrate: lipid and protein: carbohydrate ratios. Abbreviations: EtOH, ethanol; $\mathrm{P}$, proteins; C, carbohydrates; Li, lipids. 


\begin{tabular}{|c|c|c|c|c|c|}
\hline Yeast Food (YF) (1L) & Quantity & kcal & $\begin{array}{c}\text { protein } \\
(\mathrm{kcal})\end{array}$ & $\begin{array}{c}\text { carbohydrates } \\
(\mathrm{kcal})\end{array}$ & $\begin{array}{c}\text { lipids } \\
(\mathrm{kcal})\end{array}$ \\
\hline Yeast extract (g) & 20 & 43.4 & 23.8 & 18.7 & 0.9 \\
\hline Soy pepton (g) & 20 & 73.2 & 34.0 & 2.5 & 36.9 \\
\hline Sucrose (g) & 30 & 120.0 & 0.0 & 120.0 & 0.0 \\
\hline Glucose (g) & 60 & 232.2 & 0.0 & 228.5 & 0.0 \\
\hline Yeast (g) & 80 & 321.6 & 144.0 & 112.0 & 43.2 \\
\hline Agar (g) & 10 & 2.6 & 0.2 & 2.8 & 0.0 \\
\hline Water (mL) & \multicolumn{5}{|c|}{ fill until $1 \mathrm{~L}$} \\
\hline $0.1 \mathrm{~g} / \mathrm{mL}$ Nipagin/EtOH (mL) & 40 & \multicolumn{5}{c|}{ Add at $60^{\circ} \mathrm{C}$} \\
\hline & kcal & $\mathbf{7 9 3 . 0}$ & $\mathbf{2 0 2 . 0}$ & $\mathbf{4 8 4 . 5}$ & $\mathbf{8 1 . 0}$ \\
\cline { 2 - 6 } & $\%$ & $25 \%$ & $61 \%$ & $10 \%$ \\
\hline
\end{tabular}

\begin{tabular}{|c|c|}
\hline P:C:Li ratio & $3: 6: 1$ \\
\hline P:C ratio & $1: 2$ \\
\hline
\end{tabular}

\section{Table 2. Yeast food recipe}

Recipe for 1 liter of corn food. The calories (in kcal) brought by each ingredient have been also calculated. At the bottom, in black bold, the totals (in kcal) are shown. In blue are indicated the proportion (\%) of kcal of protein, carbohydrates or lipids on the total of amount calories. In purple are shown the protein: carbohydrate: lipid and protein: carbohydrate ratios. Abbreviations: EtOH, ethanol; $\mathrm{P}$, proteins; C, carbohydrates; Li, lipids.

\begin{tabular}{|c|c|c|c|c|c|}
\hline $\begin{array}{c}\text { Normal Food } \\
\text { (adapted from Indian Edu) } \\
(1 \mathrm{~L})\end{array}$ & Quantity & kcal & $\begin{array}{c}\text { protein } \\
(\mathrm{kcal})\end{array}$ & $\begin{array}{c}\text { carbohydrates } \\
\text { (kcal) }\end{array}$ & $\begin{array}{l}\text { lipid } \\
\text { (kcal) }\end{array}$ \\
\hline Sucrose $(\mathrm{g})$ & 22 & 88 & 0 & 88 & 0 \\
\hline Malt extract (g) & 20 & 73.4 & 4.8 & 76.96 & 0 \\
\hline Yeast $(\mathrm{g})$ & 18 & 72.36 & 32.4 & 25.2 & 9.72 \\
\hline Soy pepton $(\mathrm{g})$ & 10 & 36.6 & 17 & 1.24 & 18.45 \\
\hline Yellow cornmeal (g) & 80 & 276.8 & 25.6 & 224 & 21.6 \\
\hline Glucose $(\mathrm{g})$ & 20 & 77.4 & 0 & 76.16 & 0 \\
\hline Agar (g) & 7 & 1.82 & 0.14 & 1.96 & 0 \\
\hline Water $(\mathrm{mL})$ & \multicolumn{5}{|c|}{ fill until 1L } \\
\hline $0.1 \mathrm{~g} / \mathrm{mL}$ Nipagin/EtOH $(\mathrm{mL})$ & 40 & \multicolumn{4}{|c|}{ Add at $60^{\circ} \mathrm{C}$} \\
\hline & $\mathrm{kcal} / \mathrm{L}$ & 626.4 & 79.9 & 493.5 & 49.8 \\
\hline & \multicolumn{2}{|l|}{ 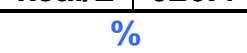 } & $13 \%$ & $79 \%$ & $8 \%$ \\
\hline
\end{tabular}

\begin{tabular}{|c|c|}
\hline P:C:Li ratio & $2: 10: 1$ \\
\hline P:C ratio & $1: 6$ \\
\hline
\end{tabular}

\section{Table 3. Normal food recipe}

Recipe for 1 liter yeast food. Quantities of each ingredient (in $\mathrm{g}$ or $\mathrm{mL}$ ) are indicated. The calories (in $\mathrm{kcal}$ ) brought by each ingredient have been also calculated. At the bottom, in black bold, the totals (in $\mathrm{kcal})$ are shown. In blue are indicated the proportion (\%) of kcal of protein, carbohydrates or lipids on the total of amount calories. In purple are shown the protein: carbohydrate: lipid and protein: carbohydrate ratios. Abbreviations: EtOH, ethanol; P, proteins; C, carbohydrates; Li, lipids 


\section{FIGURES}

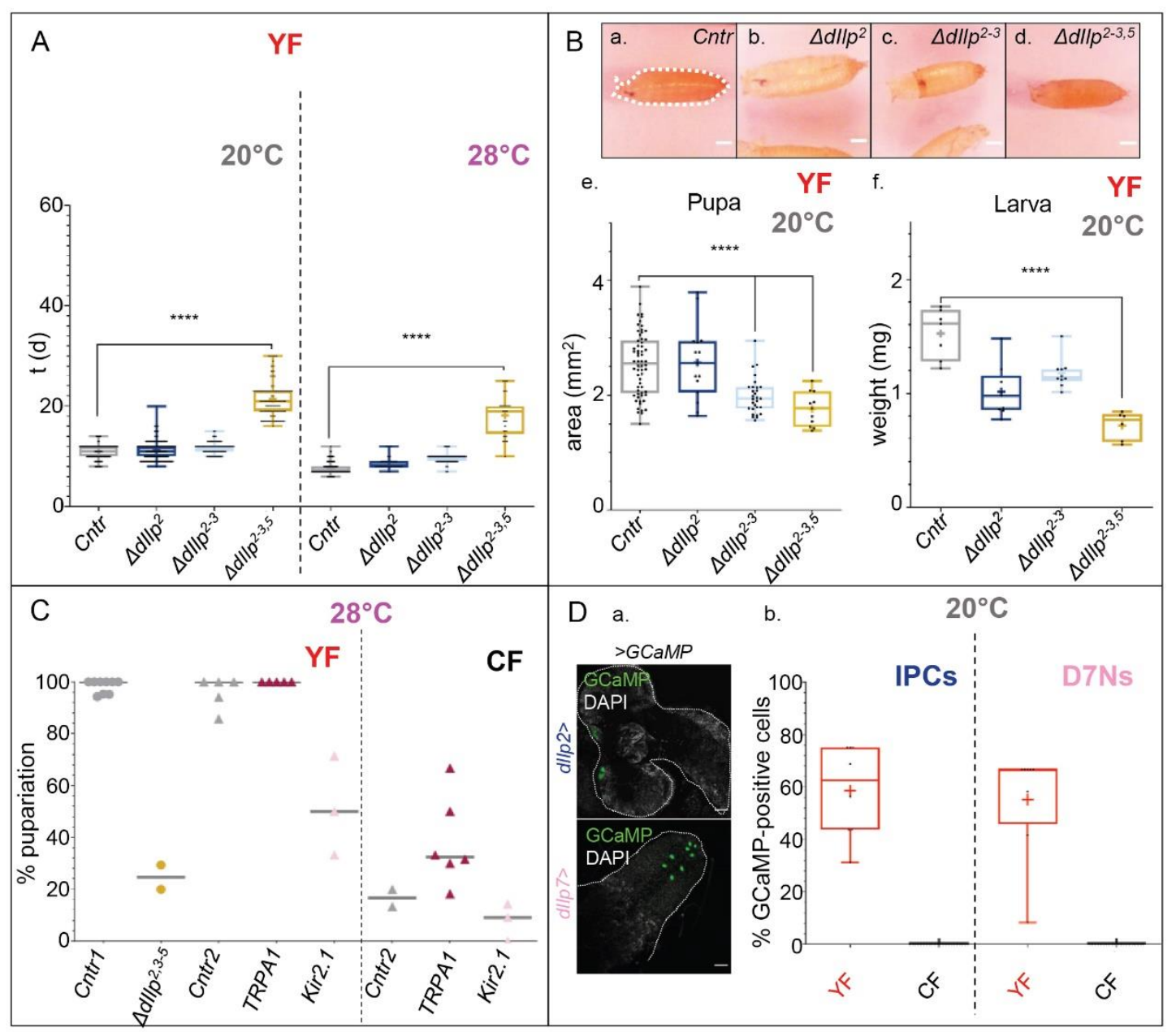

Figure 1. Activated D7Ns facilitate larval development at high temperatures

(A). Plotted is the developmental speed in days (d) to reach the pupal stage of FOXO ${ }^{\text {mCherry }}$ (Cntr, grey) and $\triangle d I l p$ mutant larvae grown on YF at 20 or $28^{\circ} \mathrm{C}$. Each black dot represents one tracked larva. Cntr (grey; median ${ }^{20^{\circ} \mathrm{C}}=11 \mathrm{~d}$; median ${ }^{28^{\circ} \mathrm{C}}=7 \mathrm{~d}$ ), $\Delta d I l p^{2}$ (dark-blue; median ${ }^{20^{\circ} \mathrm{C}}=11 \mathrm{~d} ;$ median ${ }^{28^{\circ} \mathrm{C}}=8 \mathrm{~d}$ ), $\Delta d I l p^{2-3}$ (light-blue, median ${ }^{20^{\circ} \mathrm{C}}=12 \mathrm{~d}$; median ${ }^{28^{\circ} \mathrm{C}}=10 \mathrm{~d}$ ) and $\Delta d I l p^{2-3,5}$ (yellow; median ${ }^{20^{\circ} \mathrm{C}}=21 \mathrm{~d}$; median ${ }^{28^{\circ} \mathrm{C}}=19 \mathrm{~d}$ ). Statistics: Kruskal-Wallis test $\mathrm{p}<0.0001 * * * *$; Dunn's multiple comparison test: Cntr vs $\Delta d I l p^{2}$, $\mathrm{p}^{20^{\circ} \mathrm{C}}>0.9999 \mathrm{~ns}, \mathrm{p}^{28^{\circ} \mathrm{C}}=0.0001 * * * ;$ Cntr vs $\Delta d I l p^{2-3}, \mathrm{p}^{20^{\circ} \mathrm{C}}=0.0159 *, \mathrm{p}^{28^{\circ} \mathrm{C}} 0.0001 * * * * ;$ Cntr vs $\Delta d I l p^{2-}$ $3,5: \mathrm{p}^{20^{\circ} \mathrm{C}}, \mathrm{p}^{28^{\circ} \mathrm{C}}<0.0001 * * * *$.

(B). a.-d. Shown are representative pictures of $F O X O^{m C h e r r y}$ (a, Cntr), $\Delta d I l p^{2}$ (b), $\Delta d I l p^{2-3}$ (c) and $\Delta d I l p^{2-}$ ${ }^{3,5}$ pupae (d) raised on $\mathrm{YF}$ at $20^{\circ} \mathrm{C}$. Scale bars $=0.5 \mathrm{~mm}$. e. Plotted is the area of pupae grown on $\mathrm{YF}$ at $20^{\circ} \mathrm{C}$. Each black dot represents one pupa. $C n t r$ (grey; median=2.6), $\Delta d I l p^{2}$ (dark-blue; median=2.6), $\Delta d I l p^{2-3}$ (light-blue; median=1.9) and $\Delta d I l p^{2-3,5}$ (yellow; median=1.8). Statistics: Kruskal-Wallis test $\mathrm{p}<0.0001 * * * *$; Dunn's multiple comparison test: Cntr vs $\Delta d I l p^{2}, \mathrm{p}>0.9999 \mathrm{~ns} ;$ Cntr vs $\Delta d I l p^{2-3}$, $\mathrm{p}<0.0001 * * * * ;$ Cntr vs $\Delta d I l p^{2-3,5}, \mathrm{p}<0.0001 * * * *$. f. Plotted is the larva weight per larva calculated from n pool of larvae collected and grown on $\mathrm{YF}$ at $20^{\circ} \mathrm{C}$. Each dot represents one pool. Cntr (grey; median=1.6), $\Delta d I l p^{2}$ (dark-blue; median=1,0), $\Delta d I l p^{2-3}$ (light-blue; median=1.1) and $\Delta d I l p^{2-3,5}$ (yellow; median $=0.8$ ). Statistics: Kruskal-Wallis test $\mathrm{p}<0.0001 * * * *$; Dunn's multiple comparison test: Cntr vs $\Delta d I l p^{2}, \mathrm{p}=0.0044 * * ;$ Cntr vs $\Delta d I l p^{2-3}, \mathrm{p}=0.1488 \mathrm{~ns} ;$ Cntr vs $\Delta d I l p^{2-3,5}, \mathrm{p}<0.0001 * * * *$.

(C). Plotted is the pupariation rate (\%) of larvae reared on $\mathrm{YF}$ or CF at $28^{\circ} \mathrm{C}$. FOXO ${ }^{m \text { Cherry }}$ (Cntrl, grey dots) and the $\triangle d I l p^{2-3,5}$ (yellow dots), dIlp7-Gal4/+ (Cntr2, grey triangles), dIlp7>>TRPA1 (TRPA1, dark-pink triangles) and dIlp7>>Kir2.1,tub80ts (Kir2.1, light-pink triangles). Each mark represents one experiment; the median is depicted as a grey bar. Cntrl (median=100\%), $\Delta d I l p^{2-3,5}$ (median=24.7\%), 
Cntr2 (YF, median $=100 \%$; CF, median $=16.65 \%)$, TRPAl $(\mathrm{YF}$, median $=100 \%$; CF, median $=32.45 \%$ ), Kir2.1 (YF, median=50\%; CF, median=9.10\%). Statistics: Mann-Whitney test: Cntr1 vs $\Delta d I l p^{2-3,5}$, $\mathrm{p}=0.0182$ *; Kruskal-Wallis test $\mathrm{p}=0.0031 * *$, Dunn's multiple comparison test: Cntr2 vs TRPA1, $\mathrm{p}=0.7091 \mathrm{~ns}$; Cntr vs Kir2.1, p=0.0549 ns (YF); Kruskal-Wallis test $\mathrm{p}=0.0069$ **, Dunn's multiple comparison test: Cntr2 vs TRPA1, p=0.3138 ns; Cntr vs Kir2.1, p=0.9484 ns (CF).

(D). a. Representative Z-projection confocal image of GCaMP-positive cells (green) in brains from

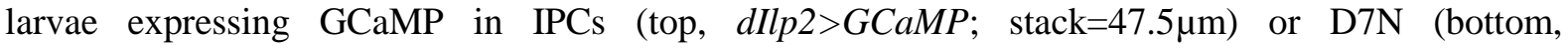
dIlp7>GCaMP; stack $=36.1 \mu \mathrm{m})$. Larvae were kept on YF at $20^{\circ} \mathrm{C}$. All samples were stained with DAPI (grey). Scale bars $=25 \mu \mathrm{m}$. b. Plotted is the percentage of GCaMP-positive IPCs or D7Ns in larvae reared

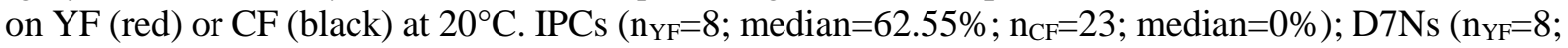
median $=66.7 \% ; \mathrm{n}_{\mathrm{CF}}=20$; median $=0 \%$ ). Statistics, Wilcoxon-test, YF vs $\mathrm{CF}, \mathrm{p}=0.0078 * *$ (IPCs, D7Ns).

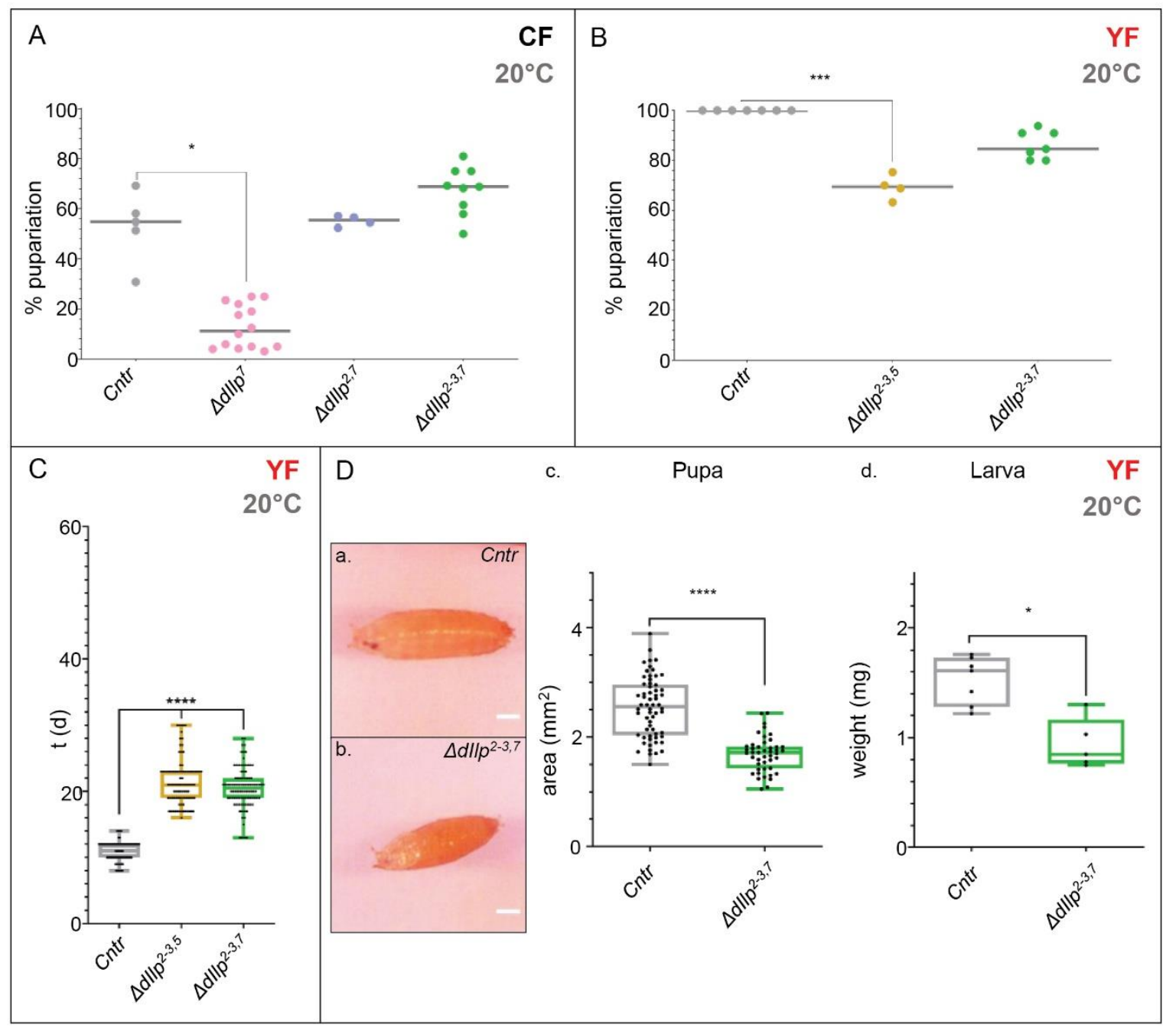

Figure 2. On CF dIIp7 peptide is instructive for IPCs

(A). Plotted is the pupariation rate in \% (median=grey bar; each dot represents one experiment) of

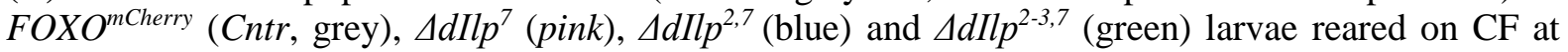
$20^{\circ}$ C. Cntr $($ median $=54.80 \%), \Delta d I l p^{7}($ median $=11.25 \%), \Delta d I l p^{2,7}($ median $=55.50 \%)$ and $\Delta d I l p^{2-3,7}$ (median $=68.80 \%$ ). Statistics: Kruskal-Wallis, $\mathrm{p}<0.0001 * * * *$; Dunn's multiple comparison test, Cntr vs $\Delta d I l p^{7}: \mathrm{p}=0.0183^{*}$, Cntr vs $\Delta d I l p^{2,7}: \mathrm{p}>0.9999 \mathrm{~ns}$, Cntr vs $\Delta d I l p^{2-3,7}: \mathrm{p}=0.8530 \mathrm{~ns}$

(B). Plotted are the pupariation rates in\% (median=grey bar; each dot represents one experiment) of $F O X O^{\text {mCherry }}$ (Cntr, grey), $\Delta d I l p^{2-3,5}$ (yellow) and $\Delta d I l p^{2-3,7}$ (green) larvae reared on YF at $20^{\circ} \mathrm{C}$. Cntr $($ median $=100 \%), \Delta d I l p^{2-3,5}($ median $=69.40 \%)$ and $\Delta d I l p^{2-3,7}$ (median=84.60\%). Statistics: Kruskal- 
Wallis, $\mathrm{p}<0.0001^{* * * *}$; Dunn's multiple comparison test, Cntr vs $\Delta d I l p^{2-3,5}: \mathrm{p}<0.0001 * * * *$, Cntr vs $\Delta d I l p^{2-3,7}: \mathrm{p}<0.0001 * * * *$.

(C). Plotted is the developmental speed in days (d) to reach the pupal stage of FOXO ${ }^{m C h e r r y}$ (Cntr, grey), $\Delta d I l p^{2-3,5}$ (yellow) and $\Delta d I l p^{2-3,7}$ (green) larvae reared on $\mathrm{YF}$ at $20^{\circ} \mathrm{C}$. Each dot represents one tracked larva. Cntr $($ median= $11 \mathrm{~d}), \Delta d I l p^{2-3,5}\left(\right.$ median=21d), $\Delta d I l p^{2-3,7}($ median=20.5d). Statistics: KruskalWallis, $\mathrm{p}<0.0001 * * * *$; Dunn's multiple comparison test, Cntr vs $\Delta d I l p^{2-3,5}: \mathrm{p}<0.0001 * * * *$, Cntr vs $\Delta d I l p^{2-3,7}: \mathrm{p}<0.0001 * * * *$.

(D). a-b. Representative pictures of $F O X O^{m C h e r r y}$ (a, Control, Cntr) and $\triangle d I l p^{2-3,7}$ (b) larvae reared on YF at $20^{\circ} \mathrm{C}$. Scale bars $=0.5 \mathrm{~mm}$. c. Area of $F O X O^{\text {mCherry }}$ (Control, Cntr, grey) and $\Delta d I l p^{2-3,7}$ (green) larvae reared on $\mathrm{YF}$ at $20^{\circ} \mathrm{C}$. Each dot represents one experiment. The area of pupae, grown on YF at $20^{\circ} \mathrm{C}$, has been measured as depicted in Fig. $1 \mathrm{Ba}$, dashed line. Cntr (median=2.6) and $\Delta d I l p^{2-3,7}$ (median=1.7). Statistics: Mann-Whitney test, $\mathrm{p}<0.0001 * * * *$. d. Plotted is the larva weight per larva calculated from n pool of larvae collected and grown on $\mathrm{YF}$ at $20^{\circ} \mathrm{C}$. Each dot represents one pool. Cntr (grey; median $=1.6$ ) and $\Delta d I l p^{2-3,7}$ (green; median=0.850). Statistics: Mann-Whitney test, $\mathrm{p}=0.0101 *$. 


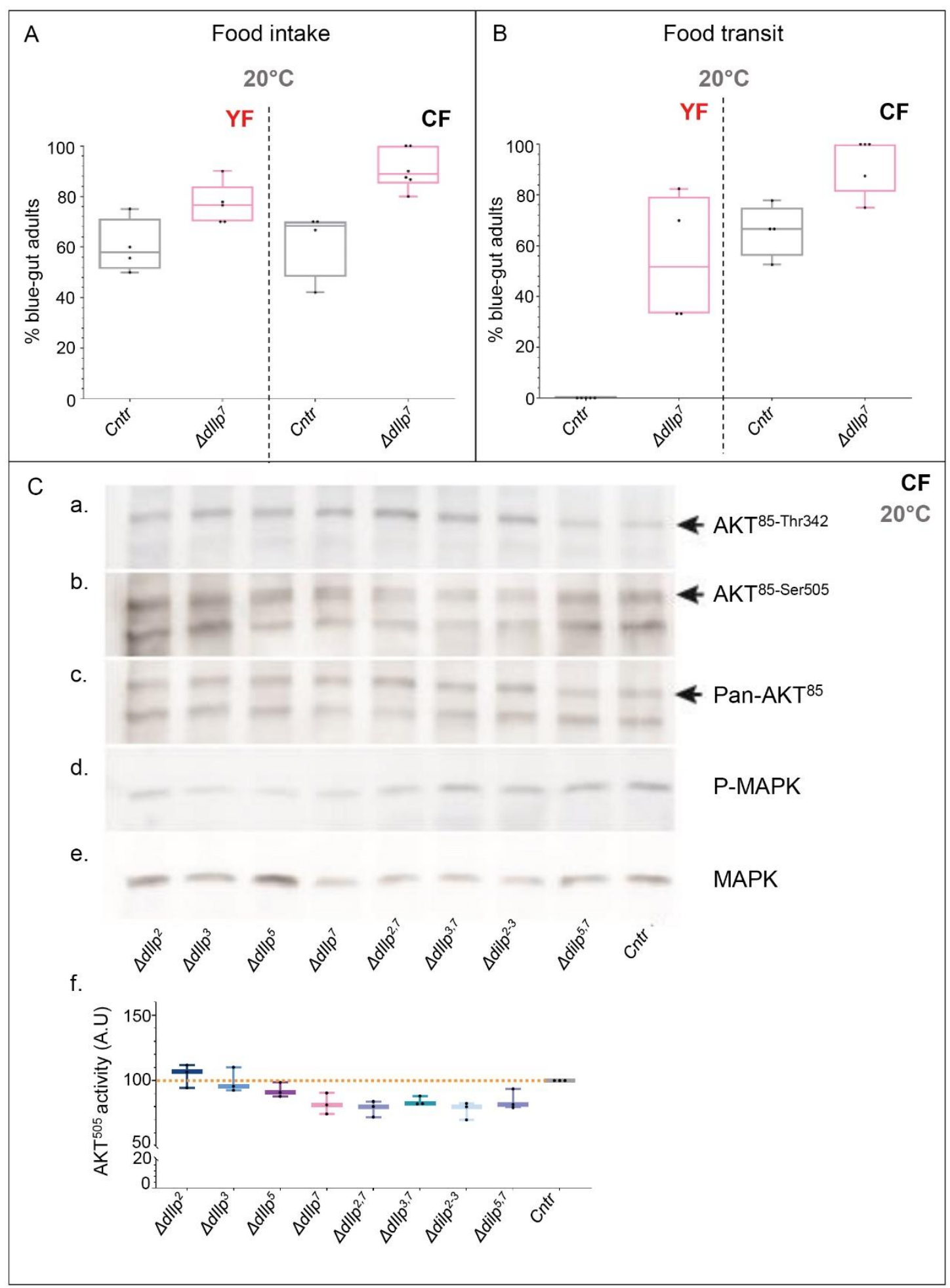

Figure 3. DIlp7 peptide regulates systemic IS on CF

(A). Plotted is the percentage of CantonS (grey, Cntr) and $\Delta d I l p^{7}$ (pink) adult females with blue guts, 4 hours after their transfer from uncoloured starvation plates to blue-stained YF (red, left) or CF (black, right $)$. Each black dot $=$ one experiment. $\operatorname{Cntr}(\mathrm{YF}$, median $=57.80 \% ; \mathrm{CF}$, median $=68.35 \%)$ and $\Delta d I l p^{7}$ (YF, median $=76.50 \%$; CF, median $=88.75 \%$ ). Statistics: Mann-Whitney test, Cntr vs $\Delta d I l p^{7}: \mathrm{p}_{\mathrm{YF}}=0.0556$ $\mathrm{ns}, \mathrm{p}_{\mathrm{CF}}=0.0095 * *$.

(B). Plotted is the percentage of CantonS (grey, Cntr) and $\Delta d I l p^{7}$ (pink) adult females with blue guts 4 hours after their transfer from blue-stained YF (red, left) or CF (black, right) to uncoloured starvation 
bioRxiv preprint doi: https://doi org/10.1101/2020.11.18.388017; this version posted November 20, 2020. The copyright holder for this preprint (which was not certified by peer review) is the author/funder, who has granted bioRxiv a license to display the preprint in perpetuity. It is made available under aCC-BY-NC-ND 4.0 International license.

plates. Each black dot $=$ one experiment. $\operatorname{Cntr}(\mathrm{YF}$, median $=0 \% ; \mathrm{CF}$, median $=66.70 \%)$ and $\Delta d I l p^{7}(\mathrm{YF}$, median $=51.65 \%$; CF, median=100\%). Statistics: Mann-Whitney test, Cntr vs $\Delta d I l p^{7}: \mathrm{p}_{\mathrm{YF}}=0.0079 * *$, $\mathrm{p}_{\mathrm{CF}}=0.0317 *$.

(C). a-e. The phosphorylation states of $\mathrm{AKT}^{85}$ (a-c; marked by arrow) and MAPK (d, e) in Control $\left(\right.$ Cntr, FOXO $\left.{ }^{\text {mCherry }}\right)$ and $\triangle d I l p$ mutants kept on $\mathrm{CF}$ at $20^{\circ} \mathrm{C}$ were analysed by western blotting. Shown is the phosphorylation at the $\mathrm{Thr}^{342}\left(\mathrm{a}, \mathrm{AKT}^{85-\mathrm{Th} 342}\right)$, the $\mathrm{Ser}^{505}\left(\mathrm{~b}, \mathrm{AKT}^{85-\mathrm{Ser} 505}\right)$ site and total amount of $\mathrm{AKT}^{85}$ (c, Pan-AKT). In addition, phosphorylation (d.) and total yields (e.) of MAPK were detected. . f. The activity at the $\mathrm{AKT}^{85-\mathrm{Ser} 505}$ was quantified (in arbitrary units, A.U.) from 3 independent blots; each black dot=one experiment. Plotted is the relative activity of each genotype normalized to the control FOXO ${ }^{m \text { Cherry }}$ (Cntr, grey, median=100\%). $\Delta d I l p^{2}$ (dark-blue, median=106.7\%), $\Delta d I l p^{3}$ (blue, median $=95.60 \%), \Delta d I l p^{5}$ (dark-purple, median=91.10\%), $\Delta d I l p^{7}$ (pink, median=81.40\%), $\Delta d$ Ill $p^{2,7}$ (blue, median=80.10\%), $\Delta d I l p^{3,7}$ (green-blue, median=82.40\%), $\Delta d I l p^{2-3}$ (light-blue, median=79.90\%), $\Delta d I l p^{5,7}$ (light-purple, median $=81.80 \%$ ). Statistics: Kruskal-Wallis test, $\mathrm{p}=0.0120 *$; Dunn's multiple comparison test, Cntr vs $\Delta d I l p^{2}, \Delta d I l p^{3}, \Delta d I l p^{5}: \mathrm{p}>0.9999 \mathrm{~ns}$, Cntr vs $\Delta d I l p^{7}: \mathrm{p}=0.1883 \mathrm{~ns}$, Cntr vs $\Delta d I l p^{2,7}: \mathrm{p}=0.0934 \mathrm{~ns}$, Cntr vs $\Delta d I l p^{3,7}: \mathrm{p}=0.5113 \mathrm{~ns}$, Cntr vs $\Delta d I l p^{2-3}: \mathrm{p}=0.0596 \mathrm{~ns}$, Cntr vs $\Delta d I l p^{5,7}$ : $\mathrm{p}=0.3579 \mathrm{~ns}$. 


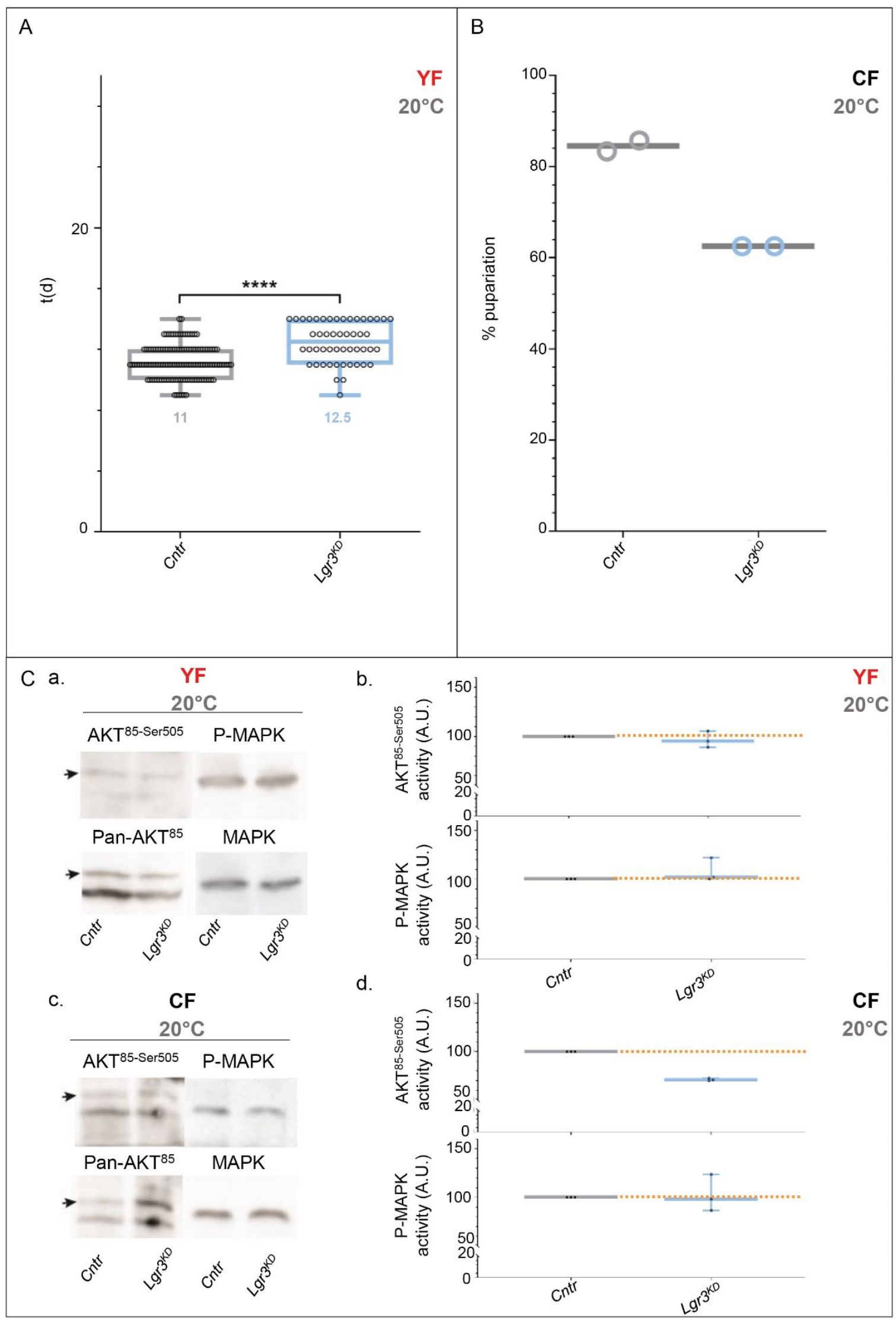




\section{Figure 4. DIlp7 targets Lgr3 expressed by IPCs}

(A, B). Plotted is the developmental speed in days $(\mathrm{d}, \mathrm{A})$ and the pupariation rate $(\%, \mathrm{~B})$ of control dIlp2-Gal4/+ (Cntr, grey) and dIlp2 >>Lgr3RNAi ( $\operatorname{Lgr} 3^{K D}$, light-blue) larvae reared on YF (A) or on $\mathrm{CF}(\mathrm{B})$ at $20^{\circ} \mathrm{C}$. A. Each black dot $=$ one larva, the median is indicated. Cntr (median=11d) and $\operatorname{Lgr} 3^{K D}$ (median=12.5d). Statistics: Mann-Whitney test: $\mathrm{p}<0.0001 * * * *$. B. Each dot $=$ one experiment. The median is indicated. Cntr (grey, median=84.5\%) and $\operatorname{Lgr}^{K D}$ (light-blue median=62.5\%).

(C). Shown are blots probed for AKT (a.) and MAPK (c.) of Control (Cntr, FOXO ${ }^{\text {mCherry }}$ ) and dIlp2 >> Lgr3RNAi $\left(\operatorname{Lgr} 3^{K D}\right)$ flies. Flies were raised on YF $(\mathrm{a}, \mathrm{b})$ or $\mathrm{CF}(\mathrm{c}, \mathrm{d})$ at $20^{\circ} \mathrm{C}$. The phosphorylation at the $\mathrm{AKT}^{85-\mathrm{Ser} 505}$ and P-MapK site was quantified and relative activity plotted (b,d). each black dot $=$ one experiment. Statistics: Mann-Whitney test, Cntr vs $L g r 3^{K D}, \mathrm{AKT}^{85-\mathrm{Ser} 505}: \mathrm{p}=0.1000$ ns; P-MAPK: p=0.7000 ns. On CF (d), $\operatorname{Lgr}^{K D}$ (n-w=3; $\mathrm{AKT}^{85-S e r 505}$, median=70.80\%; P-MAPK, median=98.20\%). Statistics, Mann-Whitney test, Cntr vs Lgr $3^{K D}$, AKT ${ }^{85-S e r 505}: \mathrm{p}=0.7000$ ns; P-MAPK: $\mathrm{p}=0.1000 \mathrm{~ns}$.

\section{REFERENCES}

1. Brankatschk M, Gutmann T, Knittelfelder O, Palladini A, Prince E, Grzybek M, et al. A temperature-dependent switch in feeding preference improves Drosophila development and survival in the cold. Dev Cell. 2018;46(6):781-93.

2. Carvalho M, Sampaio JL, Palm W, Brankatschk M, Eaton S, Shevchenko A. Effects of diet and development on the Drosophila lipidome. Mol Syst Biol [Internet]. 1 janv 2012;8(1). Disponible sur: http://msb.embopress.org/content/8/1/600.abstract

3. Knittelfelder O, Prince E, Sales S, Fritzsche E, Wöhner T, Brankatschk M, et al. Sterols as dietary markers for Drosophila melanogaster. Biochim Biophys Acta BBA - Mol Cell Biol Lipids. 1 juill 2020;1865(7):158683.

4. Watanabe K, Kanaoka Y, Mizutani S, Uchiyama H, Yajima S, Watada M, et al. Interspecies Comparative Analyses Reveal Distinct Carbohydrate-Responsive Systems among Drosophila Species. Cell Rep. 3 sept 2019;28(10):2594-2607.e7.

5. Good TP, Tatar M. Age-specific mortality and reproduction respond to adult dietary restriction in Drosophila melanogaster. J Insect Physiol. 1 déc 2001;47(12):1467-73.

6. Stanley RG, Linskens H. Organic acids, lipids and sterols. In: Pollen. Springer; 1974. p. 145-53.

7. Manning R. Fatty acids in pollen: a review of their importance for honey bees. Bee World. 1 janv 2001;82(2):60-75.

8. Menéndez R. How are insects responding to global warming? Tijdschr Voor Entomol. 2007; 150(2):355.

9. Rezende EL, Bozinovic F, Szilágyi A, Santos M. Predicting temperature mortality and selection in natural Drosophila populations. Science. 4 sept 2020;369(6508):1242.

10. Brankatschk M, Dunst S, Nemetschke L, Eaton S. Delivery of circulating lipoproteins to specific neurons in the Drosophila brain regulates systemic insulin signaling. Ramaswami M, éditeur. eLife. 2014;3:e02862.

11. Ikeya T, Galic M, Belawat P, Nairz K, Hafen E. Nutrient-Dependent Expression of Insulin-like Peptides from Neuroendocrine Cells in the CNS Contributes to Growth Regulation in Drosophila. Curr Biol. 6 août 2002;12(15):1293-300. 
12. Brogiolo W, Stocker H, Ikeya T, Rintelen F, Fernandez R, Hafen E. An evolutionarily conserved function of the Drosophila insulin receptor and insulin-like peptides in growth control. Curr Biol. 2001;11(4):213-21.

13. Grönke S, Clarke D-F, Broughton S, Andrews TD, Partridge L. Molecular Evolution and Functional Characterization of Drosophila Insulin-Like Peptides. Rulifson E, éditeur. PLoS Genet. févr 2010;6(2):e1000857.

14. Rulifson EJ, Kim SK, Nusse R. Ablation of Insulin-Producing Neurons in Flies: Growth and Diabetic Phenotypes. Science. 10 mai 2002;296(5570):1118.

15. Liu Y, Liao S, Veenstra JA, Nässel DR. Drosophila insulin-like peptide 1 (DILP1) is transiently expressed during non-feeding stages and reproductive dormancy. Sci Rep. 2016;6:26620.

16. Slaidina M, Delanoue R, Gronke S, Partridge L, Léopold P. A Drosophila Insulin-like Peptide Promotes Growth during Nonfeeding States. Dev Cell. 2009;17(6):874-84.

17. Liao S, Post S, Lehmann P, Veenstra JA, Tatar M, Nässel DR. Regulatory Roles of Drosophila Insulin-Like Peptide 1 (DILP1) in Metabolism Differ in Pupal and Adult Stages. Front Endocrinol. 2020;11:180.

18. Colombani J, Andersen DS, Boulan L, Boone E, Romero N, Virolle V, et al. Drosophila Lgr3 Couples Organ Growth with Maturation and Ensures Developmental Stability. Curr Biol. 19 oct 2015;25(20):2723-9.

19. Colombani J, Andersen DS, Léopold P. Secreted Peptide Dilp8 Coordinates Drosophila Tissue Growth with Developmental Timing. Science. 4 mai 2012;336(6081):582.

20. Colombani J, Raisin S, Pantalacci S, Radimerski T, Montagne J, Léopold P. A Nutrient Sensor Mechanism Controls Drosophila Growth. Cell. 19 sept 2003;114(6):739-49.

21. Garelli A, Heredia F, Casimiro AP, Macedo A, Nunes C, Garcez M, et al. Dilp8 requires the neuronal relaxin receptor Lgr3 to couple growth to developmental timing. Nat Commun. 29 oct 2015;6(1):8732.

22. Bai Hua, Kang Ping, Tatar Marc. Drosophila insulin-like peptide-6 (dilp6) expression from fat body extends lifespan and represses secretion of Drosophila insulin-like peptide-2 from the brain. Aging Cell. 18 sept 2012;11(6):978-85.

23. Nässel D, Kubrak O, Liu Y, Luo J, Lushchak O. Factors that regulate insulin producing cells and their output in Drosophila. Front Physiol. 2013;4:252.

24. Krieger M. J. B., Jahan N., Riehle M. A., Cao C., Brown M. R. Molecular characterization of insulin-like peptide genes and their expression in the African malaria mosquito, Anopheles gambiae. Insect Mol Biol. 24 mai 2004;13(3):305-15.

25. Riehle MA, Fan Y, Cao C, Brown MR. Molecular characterization of insulin-like peptides in the yellow fever mosquito, Aedes aegypti: Expression, cellular localization, and phylogeny. Peptides. 1 nov 2006;27(11):2547-60.

26. Miguel-Aliaga I, Thor S, Gould AP. Postmitotic Specification of Drosophila Insulinergic Neurons from Pioneer Neurons. PLOS Biol. März 2008;6(3):e58. 
27. Cognigni P, Bailey AP, Miguel-Aliaga I. Enteric Neurons and Systemic Signals Couple Nutritional and Reproductive Status with Intestinal Homeostasis. Cell Metab. 5 janv 2011;13(1):92-104.

28. Nässel DR, Enell LE, Santos JG, Wegener C, Johard HA. A large population of diverse neurons in the Drosophila central nervous system expresses short neuropeptide $F$, suggesting multiple distributed peptide functions. BMC Neurosci. 2008;9:90-90.

29. Yang C, Belawat P, Hafen E, Jan LY, Jan Y-N. Drosophila Egg-Laying Site Selection as a System to Study Simple Decision-Making Processes. Science. März 2008;319(5870):1679.

30. Inoue $\mathrm{YH}$, Katsube $\mathrm{H}$, Hinami Y. Drosophila Models to Investigate Insulin Action and Mechanisms Underlying Human Diabetes Mellitus. In: Yamaguchi M, éditeur. Drosophila Models for Human Diseases [Internet]. Singapore: Springer Singapore; 2018. p. 235-56. Disponible sur: https://doi.org/10.1007/978-981-13-0529-0_13

31. Slack C, Alic N, Foley A, Cabecinha M, Hoddinott MP, Partridge L. The Ras-Erk-ETSSignaling Pathway Is a Drug Target for Longevity. Cell. 2 juill 2015;162(1):72-83.

32. Berlanga-Acosta J, Iglesias-Marichal I, Rodríguez-Rodríguez N, Mendoza-Marí Y, García-Ojalvo A, Fernández-Mayola M, et al. Review: Insulin resistance and mitochondrial dysfunction following severe burn injury. Peptides. 1 avr 2020;126:170269.

33. Ben-Sahra I, Manning BD. mTORC1 signaling and the metabolic control of cell growth. Curr Opin Cell Biol. 2017/04/12 éd. avr 2017;45:72-82.

34. MacLean SJ, Andrews BC, Verheyen EM. Characterization of Dir: a putative potassium inward rectifying channel in Drosophila. Mech Dev. 2002;116(1-2):193-7.

35. Neely GG, Keene AC, Duchek P, Chang EC, Wang Q-P, Aksoy YA, et al. TrpA1 Regulates Thermal Nociception in Drosophila. PLOS ONE. 31 août 2011;6(8):e24343.

36. Roessingh S, Stanewsky R. The Drosophila TRPA1 Channel and Neuronal Circuits Controlling Rhythmic Behaviours and Sleep in Response to Environmental Temperature. Int J Mol Sci. 3 oct 2017;18(10):2028.

37. Zhang H, Liu J, Li CR, Momen B, Kohanski RA, Pick L. Deletion of insulin-like peptides causes growth defects and metabolic abnormalities. Proc Natl Acad Sci. 17 nov 2009;106(46):19617.

38. Broughton SJ, Piper MDW, Ikeya T, Bass TM, Jacobson J, Driege Y, et al. Longer lifespan, altered metabolism, and stress resistance in Drosophila from ablation of cells making insulin-like ligands. Proc Natl Acad Sci U S A. 22 févr 2005;102(8):3105-10.

39. Trautenberg LC, Knittelfelder O, Hofmann C, Shevchenko A, Brankatschk M, Prince E. How to use the development of individual Drosophila larvae as a metabolic sensor. J Insect Physiol. 1 oct 2020;126:104095.

40. Bhatt PK, Neckameyer WS. Functional analysis of the larval feeding circuit in Drosophila. J Vis Exp JoVE. 19 nov 2013;(81):e51062-e51062.

41. Veenstra JA. Similarities between decapod and insect neuropeptidomes. Pavasovic A, éditeur. PeerJ. 26 mai 2016;4:e2043. 
42. Veenstra JA, Rombauts S, Grbić M. In silico cloning of genes encoding neuropeptides, neurohormones and their putative G-protein coupled receptors in a spider mite. Insect Biochem Mol Biol. 1 avr 2012;42(4):277-95.

43. Jaszczak JS, Wolpe JB, Bhandari R, Jaszczak RG, Halme A. Growth Coordination During Drosophila melanogaster Imaginal Disc Regeneration Is Mediated by Signaling Through the Relaxin Receptor Lgr3 in the Prothoracic Gland. Genetics. 1 janv 2016;genetics.116.193706.

44. Umezaki Y, Hayley SE, Chu ML, Seo HW, Shah P, Hamada FN. Feeding-StateDependent Modulation of Temperature Preference Requires Insulin Signaling in Drosophila Warm-Sensing Neurons. Curr Biol. März 2018;28(5):779-787.e3.

45. Li Q, Gong Z. Cold-sensing regulates Drosophila growth through insulin-producing cells. Nat Commun. 9 déc 2015;6(1):10083.

46. Dason JS, Cheung A, Anreiter I, Montemurri VA, Allen AM, Sokolowski MB. Drosophila melanogaster foraging regulates a nociceptive-like escape behavior through a developmentally plastic sensory circuit. Proc Natl Acad Sci. 22 sept 2020;117(38):23286.

47. Post S, Tatar M. Nutritional Geometric Profiles of Insulin/IGF Expression in Drosophila melanogaster. PLOS ONE. 12 mai 2016;11(5):e0155628.

48. Trautenberg LC, Prince E, Maas C, Beier N, Honold F, Grzybek M, et al. Selective Phosphorylation of Akt/Protein-Kinase B Isoforms in Response to Dietary Cues. Front Cell Dev Biol. 2019;7:206.

49. Semaniuk UV, Gospodaryov DV, Feden'ko KM, Yurkevych IS, Vaiserman AM, Storey $\mathrm{KB}$, et al. Insulin-Like Peptides Regulate Feeding Preference and Metabolism in Drosophila. Front Physiol. 24 août 2018;9:1083-1083.

50. Post S, Karashchuk G, Wade JD, Sajid W, De Meyts P, Tatar M. Drosophila InsulinLike Peptides DILP2 and DILP5 Differentially Stimulate Cell Signaling and Glycogen Phosphorylase to Regulate Longevity. Front Endocrinol. 2018;9:245.

51. Taborsky GJ Jr. Islets have a lot of nerve! Or do they? Cell Metab. 6 juill $2011 ; 14(1): 5-6$.

52. Rodriguez-Diaz R, Abdulreda MH, Formoso AL, Gans I, Ricordi C, Berggren P-O, et al. Innervation Patterns of Autonomic Axons in the Human Endocrine Pancreas. Cell Metab. 6 juill 2011;14(1):45-54.

53. Schindelin J, Arganda-Carreras I, Frise E, Kaynig V, Longair M, Pietzsch T, et al. Fiji an Open Source platform for biological image analysis. Nat Methods. 28 juin 2012;9(7):10.1038/nmeth.2019.

54. Bligh EG, Dyer WJ. A Rapid Method Of Total Lipid Extraction And Purification. Can J Biochem Physiol. 1 août 1959;37(8):911-7.

55. Folch J, Lees M, Stanley GHS. A Simple Method For The Isolation And Purification Of Total Lipides From Animal Tissues. J Biol Chem. 1 mai 1957;226(1):497-509. 